\title{
What's the right thing to do? Increasing pro-sociality with simple moral nudges
}

\author{
Valerio Capraro ${ }^{1}$, Glorianna Jagfeld ${ }^{2}$, Rana Klein ${ }^{3}$, Mathijs $\mathrm{Mul}^{3} \&$ Iris van de $\mathrm{Pol}^{3}$ \\ ${ }^{1}$ Middlesex University of London. ${ }^{2}$ Universität Stuttgart. ${ }^{3}$ Universiteit van Amsterdam. \\ Contact Author: V.Capraro@mdx.ac.uk
}

\begin{abstract}
The conflict between pro-self and pro-social behaviour is at the core of many key problems of our time, as, for example, the reduction of air pollution and the redistribution of scarce resources. For the well-being of our societies, it is thus crucial to find mechanisms to promote pro-social choices over egoistic ones. Particularly important, because cheap and easy to implement, are those mechanisms that can change people's behaviour without forbidding any options or significantly changing their economic incentives, the so-called "nudges". Previous research has found that moral nudges (e.g., making social norms salient) can promote pro-social behaviour. However, little is known about whether their effect persists over time and spills across context. This question is key in light of research showing that prosocial actions are often followed by selfish actions, thus suggesting that some moral manipulations may backfire. Here we present a class of simple moral nudges that have a great positive impact on pro-sociality. In Studies 1-4, we use economic games to demonstrate that asking subjects to tell "what they think is the morally right thing to do" does not only increase pro-sociality in the choice immediately after, but also in subsequent choices, and even when the social context changes. In Study 5, we demonstrate that moral nudges increase charity donations by about 44 percent.
\end{abstract}

Keywords: cooperation, altruism, nudges, behavioural economics, charity donations. 


\section{Introduction}

Many decision problems involve a conflict between what is good for oneself and what is good for others. For example, reducing $\mathrm{CO}_{2}$ emissions, recycling, and donating to charity are all prosocial choices that are individually costly: they require people to pay a personal cost to benefit other people or the society as a whole (Trivers, 1971; Milinski, Semmann \& Krambeck, 2002; Gintis et al., 2003; Rand \& Nowak, 2013). Since individuals have an incentive to maximise their own benefit, finding mechanisms to reduce free-riding and promote pro-social behaviour is of great importance for the well-being of our society (Karlan \& List, 2007; Kraft-Todd et al, 2015; Martin \& Randall, 2008; Ariely, Bracha \& Meier, 2009; Capraro, 2013; Gneezy, Keenan \& Gneezy, 2014; Perc et al, 2017).

One strand of literature has focused on mechanisms such as punishing free-riders (Boyd \& Richerson, 1992; Fehr \& Gächter, 2000; Fehr \& Gächter, 2002; Gürerk, Irlenbusch \& Rockenbach, 2006), rewarding pro-socials (Panchanathan \& Boyd, 2004; Milinski et al, 2006; Capraro et al, 2016) and the interplay between these two (Andreoni, Harbaugh \&Vesterlund, 2003; Rockenbach \& Milinski, 2006; Sefton, Shupp \&Walker, 2007; Hilbe \& Sigmund, 2010). While these approaches have been shown to promote pro-sociality, and punishment has been adopted by most countries to sanction free-riders, their drawback is that they are costly. For example, in order to punish self-regarding behaviour, institutions must first pay a cost to monitor people's behaviour and find out who acted selfishly and who did not. Then they must pay a cost to punish those who acted selfishly. A similar drawback holds for rewarding pro-social actors. In order to reward pro-social actions, institutions must first pay a cost to monitor people's actions and find out who acted pro-socially and who did not; then they must pay a cost to reward those who acted pro-socially.

Thus, particularly important, from the point of view of creating societal benefit, are those mechanisms that can change people's behaviour without forbidding any options or significantly changing their economic incentives - the so-called "nudges" (Sunstein \& Thaler, 2003; Sunstein $\&$ Thaler, 2008). They are cheap and easy to implement, because they allow to avoid (i) the direct cost of changing people's economic incentives and/or limiting people's action space, (ii) the monitoring cost of finding out which choice each individual made and, possibly, the cost of punishing or rewarding each choice, and (iii) the technical difficulties associated with finding out individual choices. Thus, finding simple nudges that are able to increase pro-social behaviour is of great importance and could have impactful implications on policy design.

Here we ask the following question: How can we increase pro-social behaviour by means of simple nudges?

A large amount of research testifies of the considerable impact that norms can have on human behaviour in situations as diverse as charity donations (Croson, Handy \& Shang, 2010), alcohol consumption (Bruckner, Ecker \& Proctor, 2011), littering (Cialdini, Kallgren \& Reno, 1991), water consumption (Ferraro \& Price, 2013), risky driving (Simons-Morton et al, 2014), and many others. In short, this research suggests that people tend to follow the choice that they perceive to be the norm in a given context, which, in turn, suggests that simple reminders that 
make the morality of an action salient may have a positive impact on pro-social behaviour. Along these lines, for example, it has been shown that religious reminders favour honesty (Mazar, Amir \& Ariely, 2008) and cooperation (Rand et al, 2014; Dal Bó \& Dal Bó, 2014) in economic games. Furthermore, changing the names of the available actions to make them seem less or more moral has a large effect on people's behaviour in decision problems where there is a tension between equity and efficiency (Capraro \& Rand, 2017).

Yet, little is known about whether the effect of moral salience persists over time and spills across contexts. These are crucial questions, as there is ample evidence that some policy interventions, although effective at first, may backfire afterwards. For example, previous research has shown that people donate less to charity directly after making a choice they consider moral than after a choice they consider immoral (Gneezy, Imas \& Madarász, 2014); that "recalling one's own (im)moral behaviour leads to compensatory rather than consistent moral action" (Jordan, Mullen \& Murnighan, 2011); that "people act less altruistically and are more likely to cheat and steal after purchasing green products than after purchasing conventional products" (Mazar \& Zhong, 2010); that "people are more willing to express attitudes that could be viewed as prejudiced when their past behavior has established their credentials as nonprejudiced persons" (Monin \& Miller, 2001); see also (Sachdeva, Iliev \& Medin, 2009; Brañas-Garza et al, 2013; Merritt, Effron \& Monin, 2010; Blanken, van de Ven \& Zeelenberg, 2015). Therefore, it is crucial to find moral nudges that do not backfire by corrupting future actions, but whose effect persists over time and spills across contexts.

Here we address these questions by exploring the effect of simple moral nudges on pro-social behaviour. In our typical experiment, participants have to decide between a pro-self and a prosocial course of action, and before making their actual choice, they are asked to tell what they think is the morally right thing to do. We go beyond previous literature by not only assessing the effect of the moral nudge in the choice immediately after the nudge, but also in a second interaction, both within and across contexts, and both in the setting of economic games and in the setting of real charity donations. Importantly, we demonstrate not only that these simple moral nudges have a positive effect on the choice immediately after; but also that their effect persists to a second interaction even when the social context changes. Furthermore, we show that the use moral nudges can also be successful outside the setting of economic games: in our experiment, they significantly increased charity donations by $44 \%$.

\section{Study 1}

We begin by exploring whether moral nudges are effective in increasing altruistic behaviour in the Dictator Game (DG), a simple economic game standardly used to measure individuals' altruistic attitudes (Franzen \& Pointner, 2013; Rand et al, 2016).

\section{Subjects}

We recruit $\mathrm{N}=300$ subjects living in the US using the online labour market Amazon Mechanical Turk (AMT). AMT experiments are easy and cheap to implement, because subjects participate from their homes by simply completing an online incentivized survey that takes no more than a few minutes. This allows researchers to significantly decrease the stakes of the experiment, 
without compromising the results. Several studies have indeed shown that data gathered using AMT are of no less quality than data gathered using the standard physical lab (Paolacci, Chandler, \& Ipeirotis, 2010; Horton, Rand, Zeckhauser, 2011; Mason \& Suri, 2012; Berinsky, Uber \& Lenz, 2012; Goodman, Cryder, \& Cheema, 2013; Paolacci \& Chandler, 2014). Moreover, as an upside with respect to standard laboratory experiments, AMT experiments use samples that are more heterogeneous than the standard laboratory experiments, that are typically conducted using a pool of students. For this and the following experiments, informed consent is obtained by all participants and privacy rights are observed.

\section{Procedure}

After entering their TurkID, subjects are given 20c and are told they are paired with another subject who is given nothing. They are also told that they can donate any part of their endowment to the other subject. To make sure they understand the situation, we ask all subjects two comprehension questions regarding what choice would maximise their payoff and what choice would maximise the other person's payoff. Only those who answer both comprehension questions correctly are allowed to proceed to the experiment. Subjects are randomly divided in three conditions: $D G, D G$ personal, DGsocial. The $D G$ condition is the baseline: subjects are asked how much, if any, they want to donate to the other person. In the DGpersonal condition, right before asking subjects to state their donation, we ask them: "what do you personally think is the morally right thing to do in this situation?" In the DGsocial condition, right before asking subjects to state their donation, we ask them: "what do you think your society considers to be the morally right thing to do in this situation?" After making a choice, subjects enter a standard demographic questionnaire. After the questionnaire, subjects receive the completion code of the survey through which they can claim their bonus, that is paid on top of the participation fee (that is $40 \mathrm{c})$. We refer to the Appendix, Part 2, for full experimental instructions.

\section{Results}

The results are visualised in Figure 1, where "\% prosociality" stands for average percentage of the endowment donated. As linear regression finds no significant difference between DGpersonal and DGsocial ( $\mathrm{p}=0.473$ ), we merge these two conditions to form the DGnudged condition. When nudging subjects, average percentage of the endowment donated increases from $21.2 \%$ in the DG to $30.6 \%$ in the DGnudged ( $\mathrm{p}=0.005$ ). Thus our first study shows that moral nudges have a positive impact on altruistic behaviour in the standard DG (see Appendix, Table A1, for regression details). 


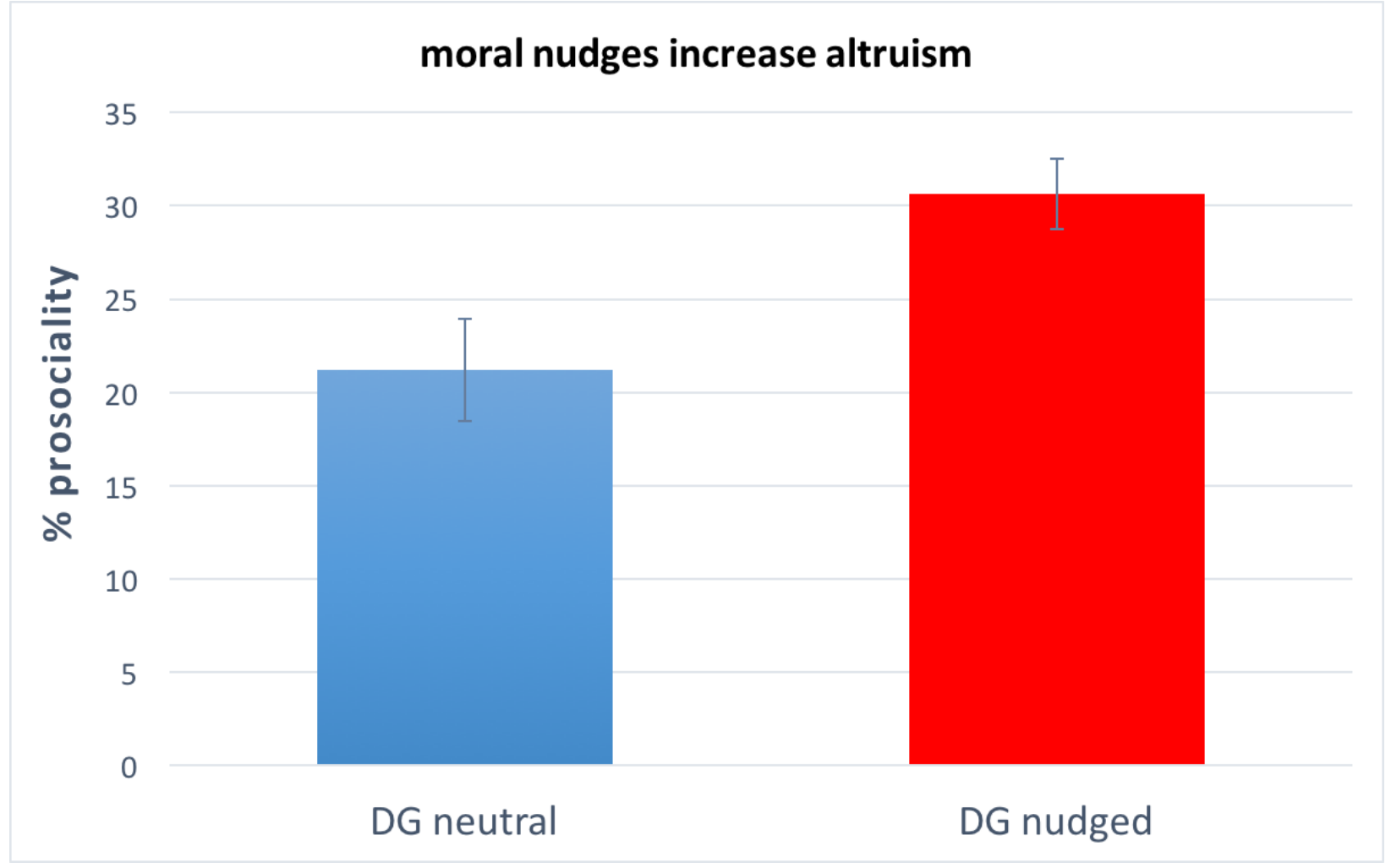

Figure 1: Moral nudges increase altruistic behaviour in Dictator games. Results of Study 1. Subjects who are asked what they personally think is the morally right thing to do or what they think their society considers to be the morally right thing to do before playing a DG (i.e., subjects in the "DG nudged" condition), donate significantly more than subjects in the baseline $D G$ ( $p=0.005)$. Error bars represent +/- SEM. We refer to the Appendix, Table A1, for regression details.

\section{Study 2}

Next we examine whether moral nudges have a positive effect also on cooperative behaviour. We design a new experiment in which the DG is replaced by a Prisoner's Dilemma (PD), an economic game standardly used to measure individuals' cooperative attitudes (Nowak, 2006; Englmaier \& Gebhardt, 2016).

\section{Subjects}

We recruit $\mathrm{N}=300$ subjects living in the US using the online labour market AMT.

\section{Procedure}

This study is identical to Study 1, apart from two changes. The first one is that the Dictator Game is replaced by a Prisoner's Dilemma (PD). In the PD, subjects are given 10c and are asked whether they want to keep it or give it to the other person. In the latter case, the $10 \mathrm{c}$ are doubled and earned by the other person. Importantly, participants are informed that the other person is 
facing exactly the same set of instructions. Thus, each participant gets a better payoff if they keep the money (defect), but, if both participants keep the money, then they only get 10c each, which is less than the 20c each that they would get if they both gave the money away (cooperate). Previous research suggests that cooperative behaviour is different from altruistic behaviour; specifically, people who act altruistically in DG typically cooperate in PD, but not the converse (Capraro, Jordan \& Rand, 2014). The second change is that, in order to participate in the experiment, subjects have to answer four comprehension questions, instead of two. We refer to the Appendix, Part 2, for full experimental instructions.

\section{Results}

As before, we build PDnudged, by merging PDpersonal with PDsocial, because average cooperation in the PDpersonal condition is not statistically different from average donation in the PDsocial condition $(\mathrm{p}=0.327)$. Results are visualised in Figure 2, where "\% prosociality" stands for the average percentage of one's own endowment given to the other player. It is clear that results are in line with those of the previous experiment: the baseline leads to the lowest average giving (32.9\%), while PDnudged give rise to a significantly higher levels of giving $(48.0 \%$, linear regression, $\mathrm{p}=0.023)$. Thus, our second study shows that moral nudges have a positive impact on cooperative behaviour in standard economic games (see Appendix, Table A2, for regression details).

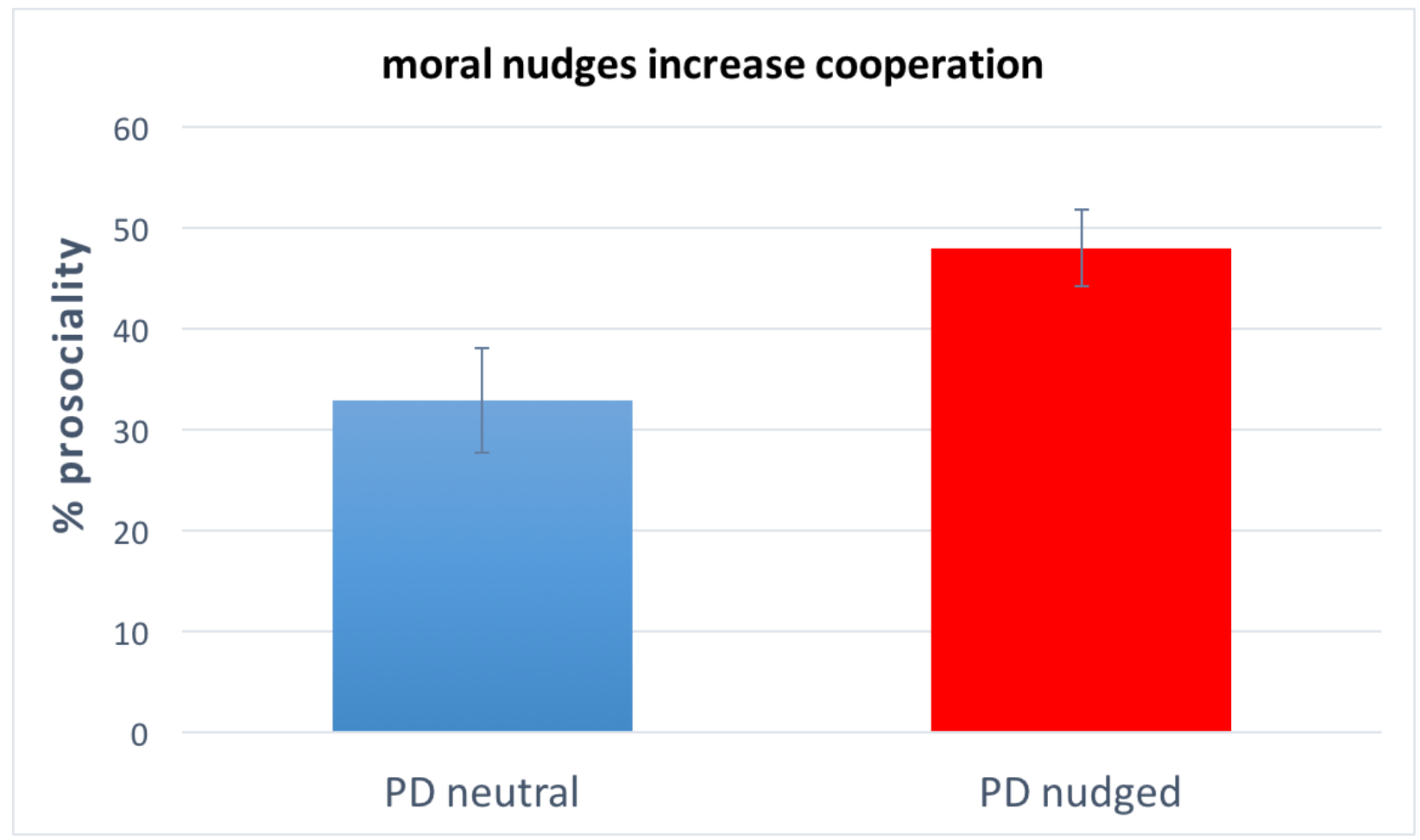

Figure 2: Moral nudges increase cooperative behaviour in the Prisoner's Dilemma. Results of Study 2. Subjects who are asked what they personally think is the morally right thing to do or what they think their society considers to be the morally right thing to do before playing a PD (i.e., subjects in the "PD nudged" condition), give significantly more than subjects in the 
baseline PD ( $p=0.023)$. Error bars represent $+/-$ SEM. We refer to the Appendix, Table A2, for regression details.

\section{Study 3}

Then we investigate whether the positive effect of moral nudges on altruistic behaviour is limited to the choice immediately after the nudge, or persists to at least one other interaction.

\section{Subjects}

We recruit $\mathrm{N}=200$ subjects living in the US using the online labour market AMT.

\section{Procedure}

Subjects played a two-stage experiment as follows. In Stage 1, they face a DG in either of two conditions: $D G$ and DGpersonal, identical to those in the first study. In Stage 2, all subjects play a standard non-nudged dictator game, denoted $D G 2$, but with slightly different instructions than the first-stage DG: dictators are given 40c (instead of 20c) and the available donations are multiple of $4 \mathrm{c}$ (instead of 2c). We opt for this variant of the Dictator game in order to avoid that people anchor their second choice to the first one (Tverski \& Kahneman, 1974), causing a confound that would be in the same direction as the effect that we expect to find.

\section{Results}

Figure 3 shows that the percentage of altruism in $D G 2$ after $D G$ is significantly lower than the percentage of altruism in DG2 after DGpersonal ( $18.0 \%$ vs $25.5 \%$; linear regression, $\mathrm{p}=0.019)$. Thus, our third study shows that the positive impact of moral nudges on altruistic behaviour is not limited to the choice immediately after the nudge, but persists to at least one other choice (see Appendix, Table A3, for regression details). 


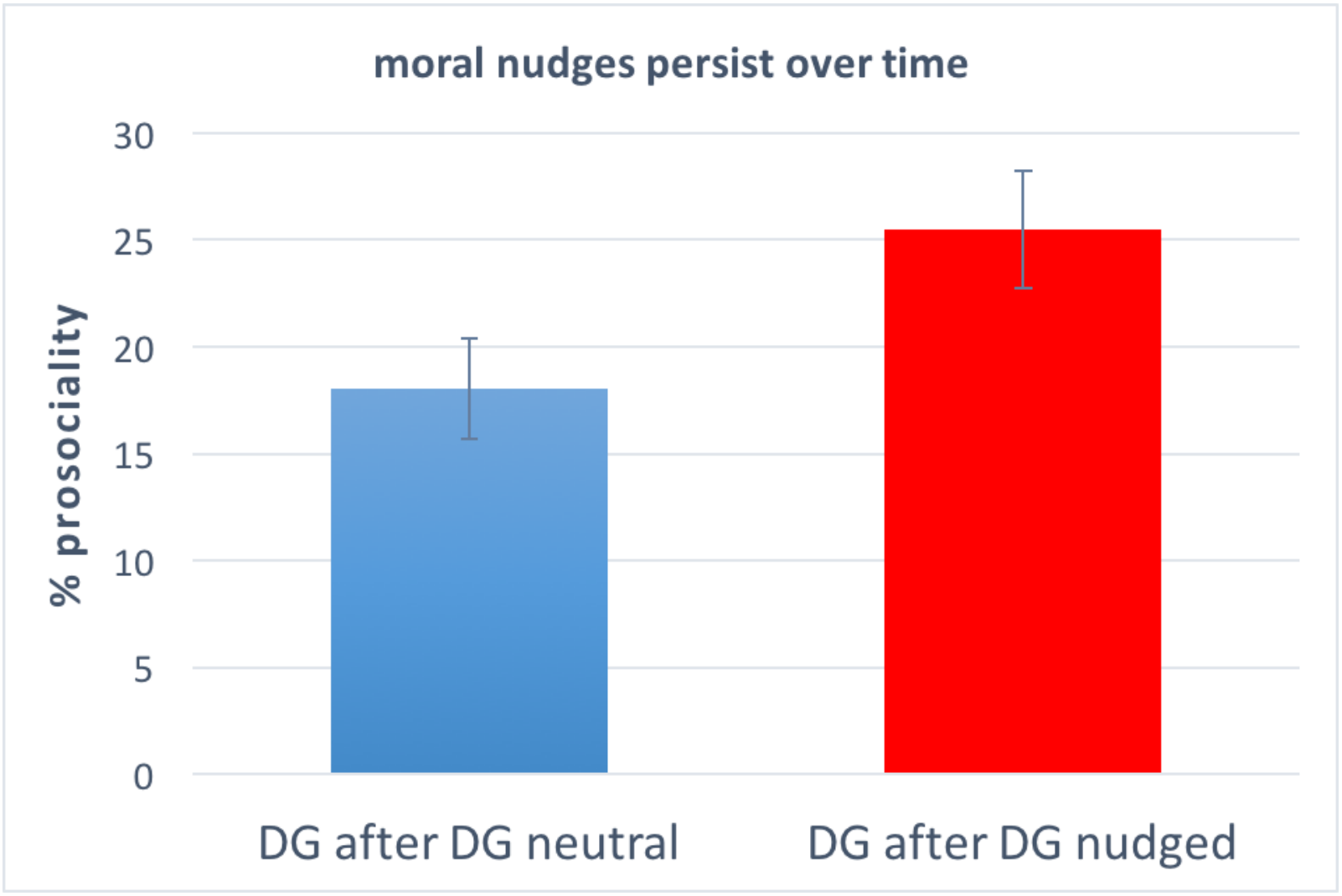

Figure 3: Moral nudges increase altruistic behaviour in a subsequent Dictator Game. Results of Study 3. The positive effect of moral nudges on altruistic behaviour in the DG is not limited to the choice immediately after the nudge, but persists to a second-stage DG, such that subjects who are nudged in Stage 1 DG donate, in a second stage DG, more than those who are not nudged $(p=0.019)$. Error bars represent +/- SEM. We refer to the Appendix, Table A3, for regression details.

\section{Study 4}

Next we explore whether the positive effect of moral nudges spills across contexts, in the sense that a moral nudge in the DG impacts also a subsequent PD and, conversely, a moral nudge in the PD impacts also a subsequent DG.

\section{Subjects}

We recruit $\mathrm{N}=600$ subjects living in the US using the online labour market AMT.

\section{Procedure}

Subjects are randomly divided in six conditions: DG- $P D$, DGpersonal- $P D$, DGsocial-PD, $P D-$ $D G, P D$ personal-DG, and $P D$ social-DG, where the notation X-Y means that subjects first play game $\mathrm{X}$ and then play game $\mathrm{Y}$. 


\section{Results}

Direct effects of the moral nudges in Stage 1 behaviour are in line with those in the previous studies. We refer to the Appendix, Table A4, for statistical details. Here we focus on the spillover effects. Figure 4 compares the percentage of the amount given in Stage 2 after the neutral condition with the percentage of the amount given in Stage 2 after the nudged conditions (i.e., in the "neutral" column we collapse DG after PD and PD after DG; while in the "nudged" column, we collapse DG after PDsocial, DG after PDpersonal, PD after DGsocial and PD after DGpersonal), and provides a first piece of evidence that moral nudges spill across contexts, as average prosociality increases from $30.9 \%$ to $36.8 \%$. Second-stage linear regression, in which the effect of moral nudges on Stage 2 behaviour is described as a proportion of the effect of moral nudges on Stage 1, shows that, when taken singularly, the effects are not significant $(D G$ after $P D$ vs $D G$ after $P D$ personal: $\mathrm{p}=0.889 ; D G$ after $P D$ vs $D G$ after $P D$ social: $\mathrm{p}=0.348 ; P D$ after $D G$ vs $P D$ after DGpersonal: $\mathrm{p}=0.110 ; P D$ after $D G$ vs $P D$ after DGsocial: $\mathrm{p}=0.309$ ). However, when meta-analysing the four conditions all together, we find a statistically significant overall effect, with a large effect size (overall effect size $=0.633,95 \%$ CI $[0.047,1.219], \mathrm{Z}=$ $2.12, p=0.034)$. In sum, our fourth study shows that about $63 \%$ of the original direct effect of moral nudges on first-stage behaviour spills over across contexts (see Appendix, Table A5, for regression details, and Appendix, Figure A1, for the forest plot of the meta-analysis).

\section{moral nudges spill across contexts}

50

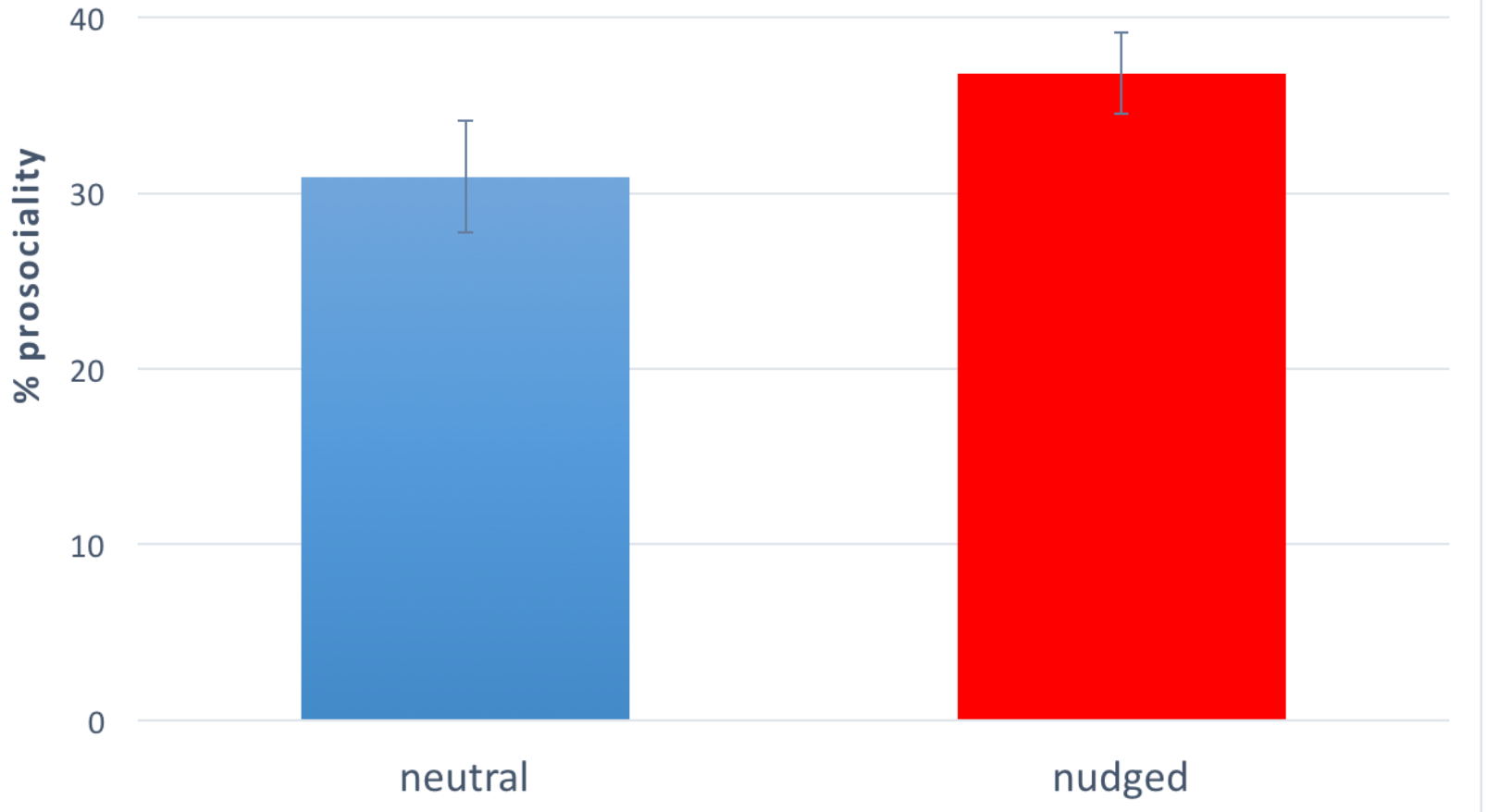


Figure 4: Moral nudges spill across contexts. Results of Study 4. Subjects who are nudged in a first-stage DG (resp. PD) tend to be more prosocial in a subsequent non-nudged PD (resp. DG) than those who are not nudged. A meta-analysis of the four conditions yields a significant positive spillover effect that is also large in size (overall effect size $=0.633,95 \% C I$ [0.047,1.219], $Z=2.12, p=0.034$ ), providing evidence that about 63\% of the effect of moral nudges on first-stage behaviour spills across contexts. Error bars represent +/- SEM. We refer to the Appendix, Table A5, for regression details, and Figure A1, for the forest plot of the metaanalysis.

\section{Study 5}

The data gathered thus far provide compelling evidence that moral nudges have a positive impact on pro-social behaviour on economic games. However, the question whether behaviour in economic games reflects behaviour in real life is still debated, with some studies finding a positive association (Benz \& Meier, 2008; Englmaier \& Gebhardt, 2016; Exadaktylos, Espín \& Brañas-Garza, 2013; Fehr \& Leibbrandt, 2011; Franzen \& Pointner, 2013), whereas others challenging this view by reporting only a weak association, if any at all (Galizzi \& NavarroMartinez, forthcoming; Gurven \& Winking, 2008; Winking \& Mizer, 2013). Thus, to strengthen our conclusions, we now provide a demonstration that our mechanism can be used to increase charity donations to real humanitarian organisations.

\section{Subjects}

We recruit $\mathrm{N}=1,800$ subjects living in the US using the online labour market AMT.

\section{Procedure}

We conduct three sessions, differing by small details, as detailed in the next paragraph, with the same basic structure. First, all subjects complete a 5-minute survey for 50c. Then they are divided between two conditions: a baseline condition and a moral nudge condition (see next paragraph for more details about the implementation of the nudges). Finally, they are divided between two more conditions, Emergency and Give for France. In the Emergency condition they are asked whether they want to donate part of their 50c to Emergency, a humanitarian NGO that provides emergency medical treatment to victims of war. In the Give for France condition, they are asked whether they want to donate part of their 50c to Give for France, an organization in support of the victims of the July 14, 2016 Nice attack. These experiments were conducted between July 15 and July 17, 2016.

The three sessions differ only on two aspects. In Session 1, subjects can donate only 0c or 50c, while in Sessions 2 and 3 they can donate any part of their 50c. Subjects who decide to donate part of their 50c are asked to abandon the current AMT survey and join a "bonus survey" in which we pay the amount that they decide not to donate as a bonus. No deception is used and the donations are really sent to the corresponding organisations. The second difference regards the way the nudge is implemented. Session 1. In the baseline condition, after the 5-minute survey, subjects are told: "thanks for answering our questions"; in the nudged condition, subjects are asked what they think is the morally right thing to do when they see a stranger in need; available 
answers: help/don't help). Session 2. The baseline condition is the same as Session 1. In the nudged condition, participants are shown the instructions of a Dictator Game and are asked what they think is the morally right thing to do in that situation. Comprehension questions on the Dictator Game are not asked. Session 3. Identical to Session 2, but we add two comprehension questions for the Dictator Game (the same as in Study 1). In order to avoid selection effects, we add two comprehension questions also in the baseline condition, that are mathematically equivalent to the questions used in the nudged condition. Specifically, we ask subjects what number $\mathrm{x}$ would maximise the expression $20-\mathrm{x}$, and what number would minimise the same expression. We refer to the Appendix, Part 2, for full experimental instructions.

\section{Results}

The results, plotted in Figure 5, provide clear evidence that morally nudged subjects give, on average, significantly more than those in the baseline (Emergency: $17.9 \%$ vs $11.7 \%, \mathrm{p}=0.029$; Give for France: $26.1 \%$ vs $16.6 \%, p=0.001$ ). The coefficients of the regressions reveal that, in the Emergency condition, donations among nudged subjects are 39\% higher than donations among non-nudged subjects, whereas, in the Give for France condition, donations among nudged subjects are $47 \%$ higher than donations among non-nudged subjects. Merging the two conditions (Emergency and Give for France), we find that moral nudges increase charity donations by about $44 \%$, on average.

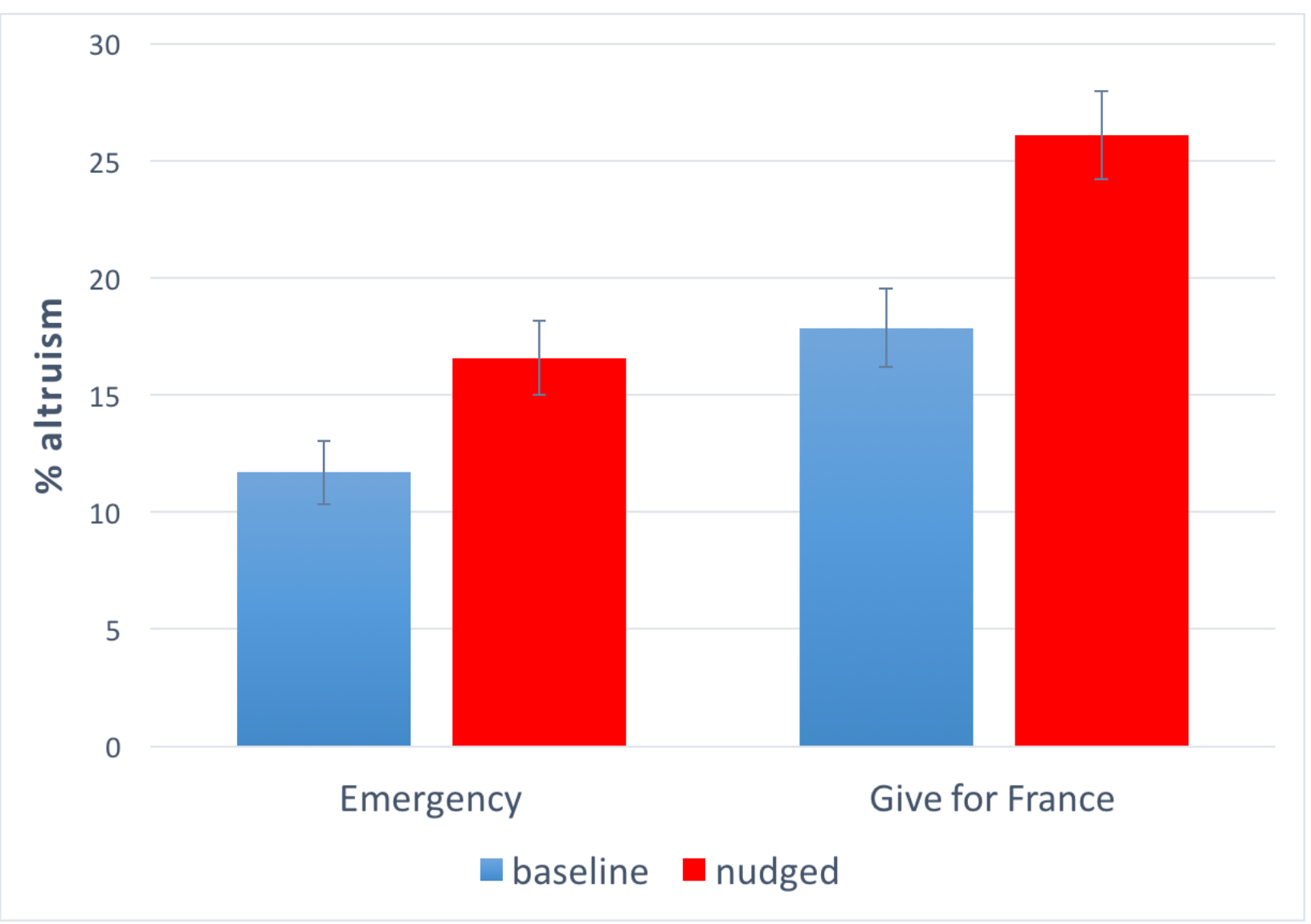


Figure 5: Moral nudges increase charity donations to real non-profit organisations. Results of Study 5. Morally nudged subjects donate significantly more to humanitarian organisations than those who are not morally nudged. This holds both when the target organisation is Emergency (in which case average donations increase from $5.85 \mathrm{c}$ to $8.29 \mathrm{c}$; coeff $=2.28, p=$ 0.029) and Give for France (in which case average donations increase from 8.93c to 13.04c; coeff $=4.20, p=0.001$ ). The coefficients are, respectively, 39\% and 47\% of the baseline donation. Merging the two conditions (Emergency and Give for France) reveals that, overall, nudging subjects increase donations by $44 \%$. Error bars represent $+/-$ SEM.

\section{Discussion}

Finding mechanisms to promote prosocial behaviour is fundamental for the well-being of our societies, and is more urgent than ever in a time of key global challenges such as resource conservation, climate change, and social inequalities (Trivers, 1971; Milinski, Semmann \& Krambeck, 2002; Gintis et al., 2003; Karlan \& List, 2007; Martin \& Randall, 2008; Ariely, Bracha \& Meier, 2009; Rand \& Nowak, 2013; Capraro, 2013; Gneezy, Keenan \& Gneezy, 2014; Kraft-Todd et al, 2015; Perc et al, 2017). Among these mechanisms, especially important, because easy and cheap to implement, are the so-called nudges, that is, mechanisms that can promote prosocial behaviour, without changing people's action space and their economic incentives (Sunstein \& Thaler, 2003; Sunstein \& Thaler, 2008).

Here we focused on moral nudges. In our experiments, participants had to decide between a proself and a pro-social course of action, but, before making their actual choice, they were asked to tell what they think is or what they think others consider to be the morally right thing to do. Our data show that these moral nudges have a positive impact on altruistic (Study 1) and cooperative (Study 2) behaviour in economic games. This positive impact is not limited to the choice made immediately after the nudge, but persists to a second interaction (Study 3) and even spills across contexts: nudging altruism in a first interaction promotes cooperation in a second, non-nudged, interaction, and nudging cooperation in a first interaction promotes altruism in a second, nonnudged, interaction (Study 4). Furthermore, this positive impact is not limited to economic games: nudging altruistic behaviour can be used to successfully increase charity donations (Study 5).

This is an important improvement over previous work. Although it has been repeatedly shown that people tend to follow what they perceive to be the norm in a given context (Cialdini, Kallgren \& Reno, 1991; Mazar, Amir \& Ariely, 2008; Croson, Handy \& Shang, 2010; Bruckner, Ecker \& Proctor, 2011; Ferraro \& Price, 2013; Simons-Morton et al, 2014; Rand et al, 2014; Dal Bó \& Dal Bó, 2014, Capraro \& Rand, 2017), little is known about whether the effect of moral nudges persists over time and spills across contexts. This question is particularly important in light of the literature on moral cleansing showing that moral actions are often followed by compensatory immoral actions (Monin \& Miller, 2001; Sachdeva, Iliev \& Medin, 2009; Mazar \& Zhong, 2010; Merritt, Effron \& Monin, 2010; Jordan, Mullen \& Murnighan, 2011; BrañasGarza et al, 2013; Gneezy, Imas \& Madarász, 2014; Blanken, van de Ven \& Zeelenberg, 2015), thus suggesting that some moral nudges may backfire. Our results show that this is not the case, at least for the moral nudges, the window of time, and the economic decisions considered in this 
paper. Not only do our moral nudges not backfire, but they even persist over time and spill across contexts.

To the best of our knowledge, only two papers have previously considered moral nudges of the type we have used in this work. Brañas-Garza (2007) found that telling DG dictators to "note that he relies on you" increases donations in the laboratory. We go beyond the results of this paper along several dimensions, as we explore the effect of moral nudges, both in the DG and in the PD, we look at its persistence over interactions and across contexts; and we also look at its effect on charity donations to humanitarian organisations. Dal Bó and Dal Bó (2014), instead, found that reminding the "Golden Rule" in the middle of a repeated PD with random rematching in groups of eight people and feedback after each round increases cooperation for a few rounds before eventually vanishing. However, the fact that the interaction is repeated in small groups with feedback after each round implies that the persistence of the increase in cooperation cannot be with certainty attributed to the persistence of the nudge. For example, it could be driven by reputation (if, for example, subjects play a Tit-for-Tat strategy conditional on the strategy they encountered in the previous interaction). We thus go much beyond the results by Dal Bó and Dal Bó (2014), in several ways: we look at the effect of moral nudges also in the DG, at its persistence across interactions while giving no feedback about the previous interaction (and therefore ruling out the potential confound of conditional strategies), at its persistence across contexts, and at its effect on charity donations to humanitarian organisations.

Our results have potentially impactful applications for policy design. Several mechanisms to promote prosocial behaviour have been explored in previous work, including giving material reward, such as a t-shirt or a mug, in exchange to a prosocial action (Ashraf, Bandiera \& Jack, 2014; Yoeli et al, 2013); augmenting donations using matching (Rondeau \& List, 2008; Meier, 2007); making people's actions observable by others (Ekström, 2012; Ernest-Jones, Nettle \& Bateson, 2011); informing people about the actions of others to make a social norm salient (Frey \& Meier, 2004; d'Adda, Capraro \& Tavoni, 2017); giving gifts while asking for a donation, in order to induce a reciprocal feeling of obligation (Falk, 2007; Gneezy \& List, 2006); soliciting people to cooperate (Andreoni, Rao \& Trachtman, 2017, Bryan et al, 2011); and many others (see Kraft-Todd et al (2015) for a review). Our results expand this list of mechanisms significantly. We show that moral nudges not only increase prosocial behaviour in the choice immediately after the nudge, but that their effect also persists over time and spills across contexts. Furthermore, compared to these studies, moral nudges have the crucial upside that they are extremely easy and cheap to implement, while still being very effective. For example, Landry et al (2006) entered people who donated to a fund-raiser into a lottery to win a personal cash prize, and found a $47 \%$ increase in the amount of money raised relative to the control condition with no lottery. Our Study 5 shows that moral nudges produce essentially the same increase (44\%), but are free of cost, that is, they allow to save the money for the prize of the lottery and the time needed to organise and conduct it.

Our findings also have some limitations, the most important of which being that they show that moral nudges increase prosocial behaviour, persist over time, and spill across contexts, but only within the window of time and choices considered in this paper, that is, two interactions (DG and PD) within the same experiment (i.e., separated by a few minutes). Future work should thus consider interactions separated by a longer time span and a greater number of interactions to 
explore the boundaries of the effectiveness of moral nudges. Furthermore, it is to be expected that the effectiveness of a moral nudge will not only depend on the particular type of nudge used, but also on the underlying social interactions. Thus, more generally, classifying moral nudges in terms of their effectiveness in different social interactions is an important direction for future research, with many applications to policy design.

Finally, our data also has theoretical applications. We have shown that people's behaviour in one-shot anonymous interactions can be influenced by moral nudges. This is in contrast to the predictions of the standard models proposed by behavioural economists to explain human prosociality in one-shot anonymous interactions. According to these models, people have preferences for minimising social inequities (Fehr \& Shmidt, 1999; Bolton \& Ockenfels, 2000), or maximising social welfare (Charness \& Rabin, 2002), or a combination of both (Charness \& rabin, 2002). These preferences are described in terms of the economic outcomes of the available actions and parameters representing the extent to which an individual cares about equity and/or efficiency. These models predict that people should be insensitive to cues about the rightness or the wrongness of an action, because these cues do not change the economic outcomes of the available actions. This prediction is not satisfied in our data: cues about what is right in a given situation can significantly change people's behaviour. Thus, our results highlight the necessity of going beyond outcome-based preferences, and speak in support of incorporating social norms into people's preferences. This is in line with an emerging strand of research suggesting that people, in their decision-making, strive for balance between maximising their material payoff and doing what they think is the morally right thing to do (Brekke, Kverndokk \& Nyborg, 2003; Huck, Kübler \& Weibull, 2012; Alger \& Weibul, 2013; Krupka \& Weber, 2013; Capraro \& Rand, 2017).

In sum, we have presented a novel technique to increase prosocial behaviour. Asking people "what's the morally right thing to do?" before they make a choice, makes the morality of an action salient. This promotes pro-sociality, and this positive effect persists to a subsequent choice, even when the social context changes. Moreover, it can successfully be used to increase donations to charitable organizations. 


\section{References}

1. d'Adda, G., Capraro, V., \& Tavoni, M. (2017). Push, don't nudge: Behavioral spillovers and policy instruments. Econ. Lett., 154, 92-95.

2. Alger, I., \& Weibull, J. (2013). Homo Moralis - Preference Evolution Under Incomplete Information and Assortative Matching. Econometrica, 81, 2269-2302.

3. Andreoni, J., Harbaugh, W., \& Vesterlund, L. (2003). The carrot or the stick: rewards, punishments, and cooperation. Am. Econ. Rev., 93, 893-902.

4. Andreoni, J., Rao, J. M., Trachtman, H. (2017). Avoiding the Ask: A Field Experiment on Altruism, Empathy, and Charitable Giving. J. Pol. Econ., 125, 625-653.

5. Ariely, D., Bracha, A., \& Meier, S. (2009). Doing good or doing well? Image motivation and monetary incentives in behaving prosocially. Am. Econ. Rev., 99, 544-555.

6. Ashraf, N., Bandiera, O., \& Jack, B. K. (2014). No margin, no mission? A field experiment on incentives for public service delivery. J. Public Econ., 120, 1-17.

7. Benz, M., \& Meier, S. (2008). Do people behave in experiments as in the field? evidence from donations. Exp. Econ., 11, 268-281.

8. Berinsky, A. J., Huber, G. A., \& Lenz, G. S. (2012). Evaluating online labor markets for experimental research: Amazon.com's Mechanical Turk. Political Anal., 20, 351-368.

9. Blanken, I., van de Ven, N., \& Zeelenberg, M. (2015). A meta-analytic review of moral licensing. Pers. Soc. Psychol. Bull., 41, 540-548.

10. Bolton, G. E., \& Ockenfels, A. (2000). ERC: A theory of equity, reciprocity, and competition. Am. Econ. Rev., 90, 166-193.

11. Boyd, R., \& Richerson, P. J. (1992). Punishment allows the evolution of cooperation (or anything else) in sizable groups. Ethol. Sociobiol., 13, 171-195.

12. Branas-Garza, P. (2007). Promoting helping behaviour with framing in dictator games. $J$. Econ. Psychol., 28, 477-486.

13. Brañas-Garza, P., Bucheli, M., Espinosa, M. P., \& Garcia-Muñoz, T. (2013). Moral cleansing and moral licenses: Experimental evidence. Econ. Phil., 29, 199-212.

14. Brekke, K. A., Kverndokk, S., \& Nyborg, K. (2003). An Economic Model of Moral Motivation. J. Public. Econ., 87, 1967-1983.

15. Bruckner, J. D., Ecker, A. H., \& Proctor, S. L. (2011). Social anxiety and alcohol problems: The roles of perceived descriptive and injunctive peer norms. J. Anxiety Disord., 25, 631-638.

16. Bryan, C. J., Walton, G. M., Rogers, T., \& Dweck, C. S. (2011). Motivating voter turnout by invoking the self. Proc. Natl. Acad. Sci., 108, 12653-12656.

17. Capraro, V. (2013). A model of human cooperation in social dilemmas. PLoS ONE, 8, e72427.

18. Capraro. V., Giardini, F., Vilone, D., \& Paolucci, M. (2016). Partner selection supported by opaque reputation promotes cooperative behavior. Judgm. Decis. Mak., 11, 589-600.

19. Capraro, V., Jordan, J. J., \& Rand, D. G. (2014). Heuristics guide the implementation of social preferences in one-shot Prisoner's Dilemma experiments. Sci. Rep., 4, 6790.

20. Capraro, V., \& Rand, D. G. (2017). Do the right thing: Preferences for moral behavior, rather than equity or efficiency per se, drive human prosociality. Available at SSRN: https://ssrn.com/abstract $=2965067$.

21. Charness, G., \& Rabin, M. (2002). Understanding social preferences with simple tests. $Q$. J. Econ., 117, 817-869. 
22. Cialdini, R.B., Kallgren, C.A., \& Reno, R. R. (1991). A Focus Theory of Normative Conduct: A Theoretical Refinement and Reevaluation of the Role of Norms in Human Behavior. Adv. Exp. Soc. Psychol., 24, 201-234.

23. Croson, R. T., Handy, F., \& Shang, J. (2010). Gendered giving: the influence of social norms on the donation behavior of men and women. Int. J. Nonprofit Volunt. Sect. Mark., $15,199-213$.

24. Dal Bó, E., \& Dal Bó, P. (2014). "Do the right thing:" The effects of moral suasion on cooperation. J. Public Econ., 117, 28-38.

25. Ekström, M. (2012). Do watching eyes affect charitable giving? Evidence from a field experiment. Exp. Econ., 15, 530-546.

26. Englmaier, F., \& Gebhardt, G. (2016). Social dilemmas in the laboratory and in the field. J. Econ. Behav. Organ., 128, 85-96.

27. Ernest-Jones, M., Nettle, D., \& Bateson, M. (2011). Effects of eye images on everyday cooperative behavior: a field experiment. Evol. Hum. Behav., 32, 172-178.

28. Exadaktylos, F., Espín, A. M., \& Branas-Garza, P. (2013). Experimental subjects are not different. Sci. Rep., 3, 1213.

29. Falk, A. (2007). Gift exchange in the field. Econometrica, 75, 1501-1511.

30. Fehr, E., \& Gächter, S. (2000). Cooperation and punishment in public goods experiments. Am. Econ. Rev., 90, 980-994.

31. Fehr, E., \& Gächter, S. (2002). Altruistic punishment in humans. Nature, 415, 137-140.

32. Fehr, E., \& Leibbrandt, A. (2011). A field study on cooperativeness and impatience in the Tragedy of the Commons. J. Public Econ., 95, 1144-1155.

33. Fehr, E., \& Schmidt, K. (1999). A theory of fairness, competition, and cooperation. Q. J. Econ., 114, 817-868.

34. Ferraro, P. J., \& Price, M. K. (2013). Using Non-Pecuniary Strategies to Influence Behavior: Evidence from a Large Scale Field Experiment. Rev. Econ. Stat., 95, 64-73.

35. Franzen, A., \& Pointner, S. (2013). The external validity of giving in the dictator game. Exp. Econ., 16, 155-169.

36. Frey, B. S., \& Meier, S. (2004). Social comparisons and pro-social behavior: testing "conditional cooperation" in a field experiment. Am. Econ. Rev., 94, 1717-1722.

37. Galizzi, M. M., \& Navarro-Martínez, D. (forthcoming) On the external validity of social preference games: A systematic lab-field study. Manag. Sci.

38. Gintis, H., Bowles, S., Boyd, R., \& Fehr, E. (2003). Explaining altruistic behavior in humans. Evol. Hum. Behav., 24, 153-172.

39. Gneezy, U., Imas, A., \& Madarász, K. (2014). Conscience accounting: Emotion dynamics and social behavior. Manag. Sci., 60, 2645-2658.

40. Gneezy, U., Keenan, E. A., \& Gneezy, A. (2014). Avoiding overhead aversion in charity. Science, 346, 632-635.

41. Gneezy, U., \& List, J. A. (2006). Putting Behavioral Economics to Work: Testing for Gift Exchange in Labor Markets Using Field Experiments. Econometrica, 74, 1365-1384.

42. Goodman, J. K., Cryder, C. E., \& Cheema, A. (2013). Data collection in the flat world: The strength and weaknesses of Mechanical Turk samples. J. Behav. Decis. Mak., 26, 213-224.

43. Gurven, M., \& Winking, J. (2008). Collective action in action: Prosocial behaviour in and out of the laboratory. Am. Anthropol., 110, 179-190. 
44. Gürerk, Ö., Irlenbusch, B., \& Rockenbach, B. (2006). The competitive advantage of sanctioning institutions. Science, 312, 108-111.

45. Hilbe, C., \& Sigmund, K. (2010). Incentives and opportunism: from the carrot to the stick. Proc. R. Soc. B, 277, 2427-2433.

46. Horton, J. J., Rand, D. G., \& Zeckhauser, R. J. (2011). The online laboratory: Conducting experiments in a real labor market. Exp. Econ., 14, 399-425.

47. Huck, S., Kübler, D., \& Weibull, J. (2012). Social norms and economic incentives in firms. J. Econ. Behav. Organ., 83, 173-185.

48. Jordan, J., Mullen, E., \& Murnighan, J. K. (2011). Striving for the moral self: The effects of recalling past moral actions on future moral behavior. Pers. Soc. Psychol. Bull., 37, 701-713.

49. Karlan, D., \& List, J. A. (2007). Does price matter in charitable giving? Evidence from a large-scale natural field experiment. Am. Econ. Rev., 97, 1774-1793.

50. Kraft-Todd, G. T., Yoeli, E., Bhanot, S., \& Rand, D. G. (2015). Promoting cooperation in the field. Curr. Opin. Behav. Sci., 3, 96-101.

51. Krupka, E. L., \& Weber, R. A. (2013). Identifying social norms using coordination games: Why does dictator game sharing vary? J. Eur. Econ. Assoc., 11, 495-524.

52. Landry, C., Lange, A., List, J. A., Price, M. K., \& Rupp, N. G. (2006). Toward an understanding of the economics of charity: Evidence from a field experiment. $Q . J$. Econ., 121, 747-782.

53. Martin, R., \& Randal, J. (2008). How is donation behaviour affected by the donations of others? J. Econ. Behav. Organ., 67, 228-238.

54. Mason, W., \& Suri, S. (2012). Conducting behavioural research on Amazon's Mechanical Turk. Behav. Res. Meth., 44, 1-23.

55. Mazar, N., Amir, O., \& Ariely, D. (2008). The dishonesty of honest people: A theory of self-concept maintenance. J. Mark. Res., 45, 633-644.

56. Mazar, N., \& Zhong, C. B. (2010). Do green products make us better people? Psychol. Sci., 21, 494-498.

57. Meier, S. (2007). Do subsidies increase charitable giving in the long run? Matching donations in a field experiment. J. Eur. Econ. Assoc., 5, 1203-1222.

58. Merritt, A. C., Effron, D. A., \& Monin, B. (2010) Moral self-licensing: When being good frees us to be bad. Soc. Personal Psychol. Compass., 4, 344-357.

59. Milinski, M., Semmann, D., \& Krambeck, H. J. (2002) Reputation helps solve the 'tragedy of the commons'. Nature, 415, 424-426.

60. Milinski, M., Semmann, D., Krambeck, H. J., \& Marotzke, J. (2006). Stabilizing the Earth's climate is not a losing game: supporting evidence from public goods experiments. Proc. Natl. Acad. Sci., 103, 3994-3998.

61. Monin, B., \& Miller, D. T. (2001). Moral credentials and the expression of prejudice. $J$. Pers. Soc. Psychol., 81, 33-43.

62. Nowak, M. A. (2006). Five rules for the evolution of cooperation. Science, 314, 15601563.

63. Panchanathan, K., \& Boyd, R. (2004). Indirect reciprocity can stabilize cooperation without the second-order free rider problem. Nature, 432, 499-502.

64. Paolacci, G., \& Chandler, J. (2014). Inside the Turk: Understanding Mechanical Turk as a participant pool. Curr. Dir. Psychol. Sci., 23, 184-188. 
65. Paolacci, G., Chandler, J., \& Ipeirotis, P. G. (2010). Running experiments on Amazon Mechanical Turk. Judgm. Decis. Mak., 5, 411-419.

66. Perc, M., Jordan, J. J., Rand, D. G., Wang, Z., Boccaletti, S., \& Szolnoki, A. (2017). Statistical physics of human cooperation. Phys. Rep., 687, 1-51.

67. Rand, D. G., Brescoll, V. L., Everett, J. A. C., Capraro, V., \& Barcelo, H. (2016). Social heuristics and social roles: Intuition favors altruism for women but not for men. $J$. Exp. Psychol. Gen., 145, 389-396.

68. Rand, D. G., Dreber, A., Haque, O. S., Kane, R. J., Nowak, M. A., \& Coakley, S. (2014). Religious motivations for cooperation: an experimental investigation using explicit primes. Religion Brain. Behav., 4, 31-48.

69. Rand, D. G., \& Nowak, M. A. (2013). Human cooperation. Trends Cogn. Sci., 17, 413425.

70. Rockenbach, B., \& Milinski, M. (2006). The efficient interaction of indirect reciprocity and costly punishment. Nature, 444, 718-723.

71. Rondeau, D., \& List, J. A. (2008). Matching and challenge gifts to charity: Evidence from laboratory and natural field experiments. Exp. Econ., 11, 253-267.

72. Sachdeva, S., Iliev, R., \& Medin, D. L. (2009). Sinning saints and saintly sinners: The paradox of moral self-regulation. Psychol. Sci., 20, 523-528.

73. Sefton, M., Shupp, R., \& Walker, J. M. (2007). The effects of rewards and sanctions in provision of public goods. Econ. Inq., 45, 671-690.

74. Simons-Morton, B. G., Bingham, C. R., Falk, E. B., Li, K., \& Pradhan, A. K. (2014). Experimental Effects of Injunctive Norms on Simulated Risky Driving Among Teenage Males. Health Psychol., 33, 616-627.

75. Sunstein, C. R., \& Thaler, R. H. (2003) Libertarian paternalism. Am. Econ. Rev., 93, 175179.

76. Sunstein, C. R., \& Thaler, R. H. (2008) Nudge: Improving decisions about health, wealth and happiness. Yale University Press.

77. Trivers, R. L. (1971). The evolution of reciprocal altruism. Q. Rev. Biol., 46, 35-57.

78. Tverski, A., \& Kahneman, D. (1974). Judgment under uncertainty: Heuristics and biases. Science, 185, 1124-1131.

79. Winking, J., \& Mizer, N. (2013). Natural-field dictator game shows no altruistic giving. Evol. Hum. Behav., 34, 288-293.

80. Yoeli, E., Hoffman, M., Rand, D. G., \& Nowak, M. A. (2013). Powering up with indirect reciprocity in a large-scale field experiment. Proc. Natl. Acad. Sci., 110, 10424-10429. 


\section{Appendix}

This Appendix is divided in two parts. In the first part, we report details of the statistical analysis. In the second part, we report full experimental instructions.

\section{Part 1. Statistical analysis}

Table A1. Linear regressions predicting Dictator Game altruism in Study 1. Participants were randomly assigned to one of three conditions: DG, DGsocial, and DGpersonal. We denote "nudged" the union between DGsocial and DGpersonal. Column (1) shows that being nudged has a significant positive effect on DG altruism. Column (2) shows that this effect is robust after controlling for sex, age, and education. Column (3) shows that the "social nudge" has a significant (at 10\%) positive effect on DG altruism. Column (4) demonstrates that this effect is robust and actually is strengthened after controlling for sex, age, and education. Columns (5) and (6) show that the "personal nudge" has a significant positive effect on DG donations.

\begin{tabular}{|c|c|c|c|c|c|c|}
\hline & \multicolumn{6}{|c|}{ Dictator Game altruism } \\
\hline & (1) & (2) & (3) & (4) & (5) & (6) \\
\hline nudged & $\begin{array}{l}0.094 * * * \\
(0.033)\end{array}$ & $\begin{array}{l}0.104 * * * \\
(0.033)\end{array}$ & & & & \\
\hline social & & & $\begin{array}{l}0.074 * \\
(0.039)\end{array}$ & $\begin{array}{l}0.086 * * \\
(0.039)\end{array}$ & & \\
\hline personal & & & & & $\begin{array}{l}0.114 * * * \\
(0.037)\end{array}$ & $\begin{array}{l}0.122 * * * \\
(0.037)\end{array}$ \\
\hline sex & & $\begin{array}{l}0.064 * * \\
(0.032)\end{array}$ & & $\begin{array}{l}0.019 \\
(0.041)\end{array}$ & & $\begin{array}{l}0.060 \\
(0.038)\end{array}$ \\
\hline age & & $\begin{array}{l}0.002 \\
(0.002)\end{array}$ & & $\begin{array}{l}0.003 \\
(0.002)\end{array}$ & & $\begin{array}{l}0.002 \\
(0.002)\end{array}$ \\
\hline education & & $\begin{array}{l}-0.014 \\
(0.012)\end{array}$ & & $\begin{array}{l}-0.017 \\
(0.015)\end{array}$ & & $\begin{array}{l}-0.021 \\
(0.014)\end{array}$ \\
\hline constant & $\begin{array}{l}0.212 * * * \\
(0.027)\end{array}$ & $\begin{array}{l}0.103 \\
(0.081)\end{array}$ & $\begin{array}{l}0.212 * * * \\
(0.028)\end{array}$ & $\begin{array}{l}0.152 \\
(0.099)\end{array}$ & $\begin{array}{l}0.212 * * * \\
(0.027)\end{array}$ & $\begin{array}{l}0.149 \\
(0.094)\end{array}$ \\
\hline obs & 282 & 282 & 188 & 188 & 184 & 184 \\
\hline r-squared & 0.028 & 0.056 & 0.019 & 0.041 & 0.048 & 0.078 \\
\hline
\end{tabular}

Note: Linear regression, robust standard error in parentheses. *: significant at $10 \%, * *$ : significant at $5 \%, * * *$ : significant at $1 \%$. 
Table A2. Linear regression predicting Prisoner's Dilemma cooperation in Study 2.

Participants were randomly assigned to one of three conditions: PD, PDsocial, and PDpersonal. We denote "nudged" the union between PDsocial and PDpersonal. Column (1) shows that being nudged has a significant positive effect on PD cooperation. Column (2) shows that this effect is robust after controlling for sex, age, and education. Columns (3) and (4) show that the "social nudge" has a significant positive effect on PD cooperation, and that this effect is robust after controlling for sex, age, and education. Columns (5) and (6) show that the "personal nudge" does not have a significant positive effect on PD cooperation (the effect, however, is close to marginally significant: both $\mathrm{p}$ 's $<0.13$. Moreover, comparing PDsocial with PDpersonal, we find no significant difference: $\mathrm{p}=0.327$ ).

\begin{tabular}{|c|c|c|c|c|c|c|}
\hline & \multicolumn{6}{|c|}{ Prisoner's Dilemma cooperation } \\
\hline & (1) & (2) & (3) & (4) & (5) & (6) \\
\hline nudged & $\begin{array}{l}0.151 * * \\
(0.066)\end{array}$ & $\begin{array}{l}0.138 * * \\
(0.066)\end{array}$ & & & & \\
\hline social & & & $\begin{array}{l}0.188 * * \\
(0.075)\end{array}$ & $\begin{array}{l}0.164 * * \\
(0.077)\end{array}$ & & \\
\hline personal & & & & & $\begin{array}{l}0.114 \\
(0.075)\end{array}$ & $\begin{array}{l}0.115 \\
(0.072)\end{array}$ \\
\hline $\operatorname{sex}$ & & $\begin{array}{l}0.126^{* *} \\
(0.061)\end{array}$ & & $\begin{array}{l}0.049 \\
(0.075)\end{array}$ & & $\begin{array}{l}0.219 * * * \\
(0.074)\end{array}$ \\
\hline age & & $\begin{array}{l}0.005^{*} \\
(0.003)\end{array}$ & & $\begin{array}{l}0.003 \\
(0.004)\end{array}$ & & $\begin{array}{l}0.008 * * \\
(0.004)\end{array}$ \\
\hline education & & $\begin{array}{l}0.016 \\
(0.025)\end{array}$ & & $\begin{array}{l}-0.038 \\
(0.032)\end{array}$ & & $\begin{array}{l}-0.011 \\
(0.028)\end{array}$ \\
\hline constant & $\begin{array}{l}0.329 * * * \\
(0.054)\end{array}$ & $\begin{array}{l}-0.096 \\
(0.168)\end{array}$ & $\begin{array}{l}0.330 * * * \\
(0.054)\end{array}$ & $\begin{array}{l}0.011 \\
(0.123)\end{array}$ & $\begin{array}{l}0.330 * * * \\
(0.054)\end{array}$ & $\begin{array}{l}-0.197 \\
(0.192)\end{array}$ \\
\hline obs & 257 & 257 & 169 & 169 & 170 & 170 \\
\hline r-squared & 0.020 & 0.053 & 0.036 & 0.041 & 0.014 & 0.103 \\
\hline
\end{tabular}

Note: Linear regression, with odds ratio and robust standard error in parentheses. *: significant at $10 \%, * *$ : significant at $5 \%, * * *$ : significant at $1 \%$. 
Table A3. Linear regression predicting second-stage Dictator Game altruism in Study 3. Participants were randomly assigned to one of two two-stage games: DG-DG2, DGpersonalDG2. We regress second-stage behavior as a function of whether subjects, in stage 1, participated in the DGpersonal condition or in the DG condition. Column (1) shows that who participated in the DGpersonal condition gave, in stage 2, more than those who participated in the DG condition. Column (2) shows that this effect is robust after controlling for sex, age, and education.

\begin{tabular}{|l|l|l|}
\hline & \multicolumn{2}{|l|}{ Stage 2 Dictator Game altruism } \\
\hline & $(\mathbf{1})$ & $(\mathbf{2})$ \\
\hline personal & $0.075^{* *}$ & $0.086^{* *}$ \\
& $(0.036)$ & $(0.036)$ \\
\hline sex & & 0.050 \\
& & $(0.035)$ \\
\hline age & & $0.004^{* *}$ \\
& & $(0.001)$ \\
\hline education & & 0.012 \\
& & $(0.015)$ \\
\hline constant & $0.180^{* * *}$ & -0.086 \\
& $(0.024)$ & $(0.109)$ \\
\hline obs & 172 & 172 \\
\hline r-squared & 0.025 & 0.073 \\
\hline
\end{tabular}

Note: Linear regression, with odds ratio and robust standard error in parentheses. *: significant at $10 \%, * *$ : significant at $5 \%, * * *$ : significant at $1 \%$. 
Table A4. List of all direct effects. Summary of all first stage manipulations we have conducted in Studies 1-4. For each manipulation, the treatment is compared with the baseline.

\begin{tabular}{|l|l|l|}
\hline & \multicolumn{2}{|c|}{ OLS coefficients } \\
\hline DGpersonal (study 1) & $\mathbf{( 1 )}$ & $\mathbf{( 2 )}$ \\
\hline DGpersonal (study 3) & $0.114^{* * *}$ & $0.122^{* *}$ \\
& $(0.037)$ & $(0.037)$ \\
\hline DGpersonal (study 4) & 0.059 & $0.068^{*}$ \\
& $(0.037)$ & $(0.037)$ \\
\hline DGsocial (study 1) & $0.091^{* *}$ & $0.097^{*}$ \\
& $(0.040)$ & $(0.041)$ \\
\hline DGsocial (study 4) & $0.074^{*}$ & $0.086^{* *}$ \\
& $(0.039)$ & $(0.039)$ \\
\hline PDpersonal (study 2) & 0.061 & 0.063 \\
& $(0.040)$ & $(0.040)$ \\
\hline PDpersonal (study 4) & 0.114 & 0.115 \\
& $(0.075)$ & $(0.072)$ \\
\hline PDsocial (study 2) & 0.075 & 0.061 \\
& $(0.079)$ & $(0.080)$ \\
\hline PDsocial (study 4) & $0.188^{* *}$ & $0.164 * *$ \\
& $(0.075)$ & $(0.077)$ \\
\hline overall effect on DG (meta-analysis) & $0.146^{*}$ & $0.135^{*}$ \\
\hline overall effect on PD (meta-analysis) & $(0.078)$ & $(0.078)$ \\
\hline control on demographics & $0.080^{* * *}$ & $0.088^{* * *}$ \\
\hline Note: Lin & $0.132^{* * *}$ & $0.120^{* * *}$ \\
\hline
\end{tabular}

Note: Linear regression, with odds ratio and robust standard error in parentheses. *: significant at $10 \%, * *$ : significant at $5 \%, * * *$ : significant at $1 \%$. 
Table A5. List of all spillover effects. Summary of all spillover effects in Study 4. Since spillover effects in Stage 2 depend on Stage 1 direct effects, in order to compute the coefficients of the spillover effect we use second-stage linear regression, which allows us to express secondstage effects as a proportion of first stage effects. To use second-stage linear regression, we need to re-normalize DG donations by multiplying them by 2 (because PD cooperation goes from 0 to 1 , while DG altruism goes from 0 to 0.5 ). For each manipulation, the treatment is compared with the baseline. Spillover effects are all in the same direction, although none of them is statistically significant when taken singularly. However, when meta-analyzing them together, we find a significant effect which is also big in size.

\begin{tabular}{|l|l|l|}
\hline & \multicolumn{2}{|c|}{ OLS coefficients } \\
\hline DGpersonal-PD & $\mathbf{( 1 )}$ & $\mathbf{( 2 )}$ \\
\hline DGsocial-PD & 0.694 & 0.653 \\
& $(0.432)$ & $(0.415)$ \\
\hline PDpersonal-DG & 0.658 & 0.647 \\
& $(0.648)$ & $(0.634)$ \\
\hline PDsocial-DG & 0.166 & 0.451 \\
& $(1.191)$ & $(1.470)$ \\
\hline overall effect (meta-analysis) & 0.553 & 0.604 \\
\hline control on demographics & $(0.587)$ & $(0.641)$ \\
\hline
\end{tabular}

Note: Second-stage linear regression, with robust standard error in parentheses. *: significant at $10 \%, * *$ : significant at $5 \%, * * *$ : significant at $1 \%$. 


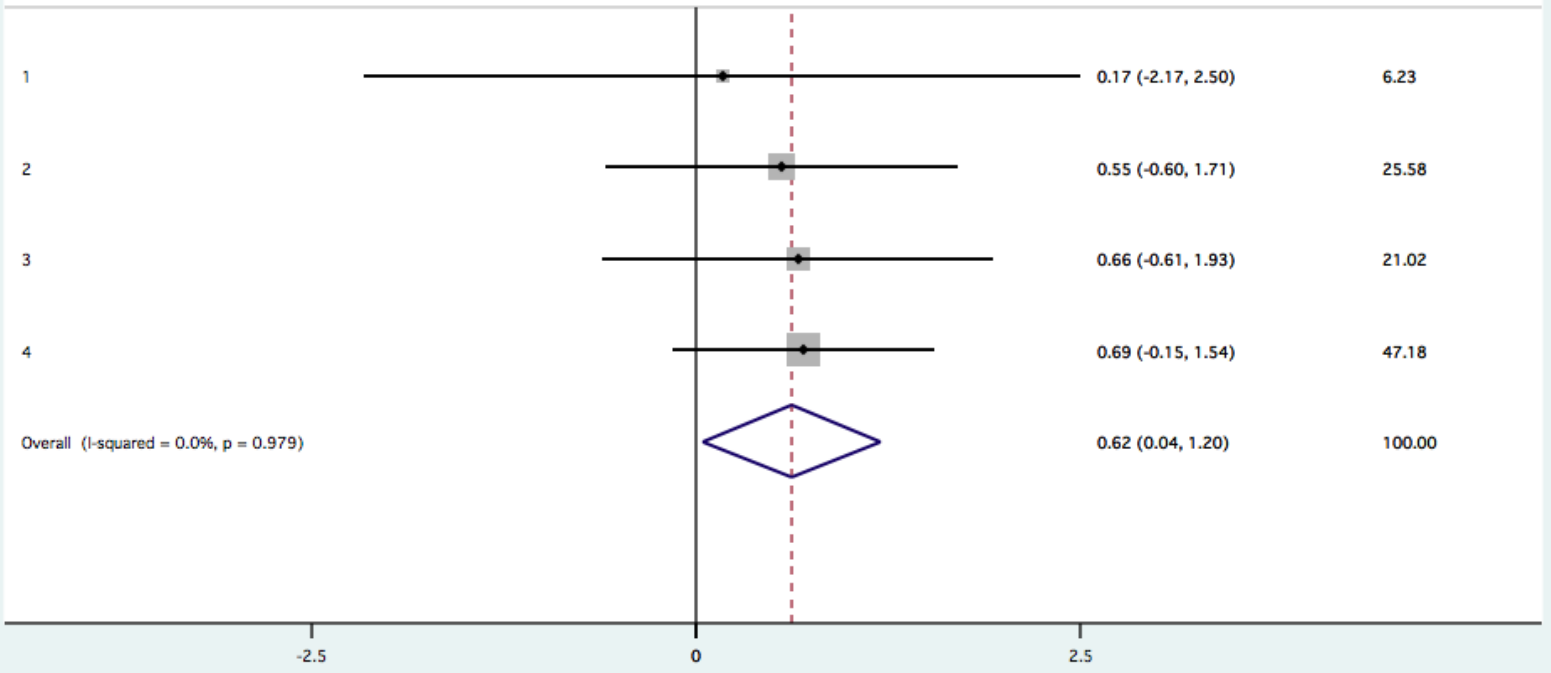

Figure A1: Forest plot of the meta-analysis of Study 4. Study ID = 1 compares average cooperation in PD played after DG personal with average cooperation in PD played after DG neutral. Study ID = 2 compares average cooperation in PD played after DG social with average cooperation in PD played after DG neutral. Study ID = 3 compares average altruism in DG played after PD social with average altruism in DG played after PD neutral; finally, Study ID = 4 compares average altruism in DG played after PD personal with average altruism in DG played after PD neutral. All the effects are in the same direction, meaning that in all four cases, the average prosociality in games played in Stage 2 after a moral nudge is implemented in Stage 1 is numerically higher than average prosociality in games played in Stage 2 after no moral nudge is implemented in Stage 1. None of these effects is statistically significant when taken singularly (DG after PD vs DG after PDpersonal: $p=0.889 ; D G$ after PD vs DG after PDsocial: $p=0.348$; PD after DG vs PD after DGpersonal: $p=0.110 ;$ PD after DG vs PD after DGsocial: $p=0.309)$. However, meta-analysis shows that there is a significant overall effect (overall effect size $=0.633,95 \%$ CI [0.047,1.219], $Z=2.12, p=0.034$ ), that is also big in size: about $63 \%$ of the original effect of moral nudges spill across contexts. 


\section{Part 2. Experimental instructions}

\section{Study 1}

\section{$\underline{D G}$ instructions and comprehension questions (common to all treatments)}

Please read these instructions carefully. You may earn a considerable bonus, depending on the decision you make.

You have been paired with another participant. The amount of money you can earn depends only on your choice. You are given 20c and the other participant is given nothing. You have to decide how much, if any, to transfer to the other participant.

The other participant is REAL, and has no choice but to accept the amount of money you decide to transfer.

No deception is used. You will really get the amount of money you decide to keep.

Here are some questions to ascertain that you understand the rules. Remember that you have to answer all of these questions correctly in order to get the completion code. If you fail any of them, the survey will automatically end and you will not have a chance to earn a bonus.

What is the transfer by YOU that maximizes YOUR bonus? (Available answers: 0c/2c/.../20c)

What is the transfer by YOU that maximizes the OTHER PARTICIPANT's bonus? (Available answers: $0 \mathrm{c} / 2 \mathrm{c} / \ldots / 20 \mathrm{c}$ )

(Here there was a display logic, such that participants were automatically eliminated if they failed one of the previous comprehension questions. In case they were not eliminated, the survey proceeded to the next screen)

Congratulations, you have answered both comprehension questions correctly!

\section{$\underline{\text { DG neutral }}$}

It is now time to make your choice.

What amount will you transfer to the other person? (Available answers: 0c/2c/.../20c)

\section{$\underline{\text { D personal }}$}

What do you personally think is the morally right thing to do in this situation?

Transfer:

(Available answers: 0c/2c/...20c) 
It is now time to make your choice.

What amount will you transfer to the other person? (Available answers: 0c/2c/.../20c)

\section{$\underline{\text { DG social }}$}

What do you think your society considers to be the morally right thing to do in this situation?

Transfer:

(Available answers: 0c/2c/...20c)

It is now time to make your choice.

What amount will you transfer to the other person? (Available answers: 0c/2c/.../20c)

\section{Study 2}

\section{$\underline{P D \text { instructions and comprehension questions (common to all treatments) }}$}

Please read these instructions carefully. You may earn a considerable bonus, depending on the decisions you and another participant make.

You have been paired with another anonymous participant. You are both given 10c and each of you must decide whether to transfer the $10 \mathrm{c}$ or not. If a participant transfers their $10 \mathrm{c}$, this amount will be doubled, and given to the other participant.

So:

- If you both decide to transfer the 10c, you end this part of the survey with a bonus of 20 c.

- If the other participant transfers the $10 \mathrm{c}$ and you do not, you end this part of the survey with a bonus of 30c.

- If you transfer the $10 \mathrm{c}$ and the other participant does not, you end this part of the survey with a bonus of 0 c.

- If neither of you transfer the 10c, then you end this part of the survey with a bonus of $10 c$.

The other participant is REAL, and you and the other participant are really going to get a bonus depending on the decisions that you and the other participant will make.

Here are some questions to ascertain that you understand the rules. Remember that you have to answer all of these questions correctly in order to get the completion code. If you fail any of them, the survey will automatically end and you will not have a chance to earn a bonus.

What choice should YOU make to maximise YOUR gain? (available answers: transfer the $10 \mathrm{c} /$ don't transfer the 10c) 
What choice should YOU make to maximise the OTHER PARTICIPANT's gain? (available answers: transfer the 10c/don't transfer the 10c)

What choice should the OTHER PARTICIPANT make to maximise THEIR gain? (available answers: transfer the 10c/don't transfer the 10c)

What choice should the OTHER PARTICIPANT make to maximise YOUR gain? (available answers: transfer the 10c/don't transfer the 10c)

(Here there was a display logic, such that participants were automatically eliminated if they failed one of the previous comprehension questions. In case they were not eliminated, the survey proceeded to the next screen)

Congratulations, you have answered both comprehension questions correctly!

\section{PD neutral}

It is now time to make your choice. (available answers: transfer the 10c/don't transfer the 10c)

PD personal

What do you personally think is the morally right thing to do in this situation? (available answers: transfer the 10c/don't transfer the 10c)

It is now time to make your choice. (available answers: transfer the 10c/don't transfer the 10c)

\section{PD social}

What do you think your society considers to be the morally right think to do in this situation? (available answers: transfer the 10c/don't transfer the 10c)

It is now time to make your choice. (available answers: transfer the 10c/don't transfer the 10c)

\section{Study 3}

The DG and DGpersonal conditions were identical to those of Study 1.

\section{$\underline{D G 2 \text { condition (common to all participants) }}$}

This is the second part of the HIT.

Please read these instructions carefully. You may earn a considerable bonus, depending on the decision you make.

You have been paired with another participant, different from the one you were paired with in 
the previous part of the HIT. The amount of money you can earn depends only on your choice. You are given 40c and the other participant is given nothing. You have to decide how much, if any, to transfer to the other participant.

The other participant is REAL, and has no choice but to accept the amount of money you decide to transfer.

No deception is used. You will really get the amount of money you decide to keep.

What amount will you transfer to the other person? (Available answers: 0c/4c/8c/.../40c)

\section{Study 4}

The PD, PDsocial, PDpersonal, DG, DGsocial, and DGpersonal conditions are identical to those of Study 1 and Study 2.

\section{Study 5, Session 1}

\section{Welcome screen (common to all subjects)}

Welcome to this HIT.

This HIT consists of a set of questions. Answering these questions will take about five minutes.

For the participation in this HIT, you will earn 50c.

With this in mind, do you wish to continue?

Survey (common to all subjects whose goal is to create a sense of endowing the 50c)

Gender: (available answers: male/female)

Age: (open answer)

Highest level of education completed: (available answers: less than a high school degree/high school diploma/vocational training/attended college/bachelor's degree/graduate degree/unknown)

Please choose the category that describes the total amount of income you earned in 2015. Consider all forms of income, including salaries, tips, interest and dividend payments, scholarship support, student loans, parental support, social security, alimony, and child support, and others. (\$5,000-\$10,000/\$10,001-\$15,000/\$15,001-\$25,000/\$25,001-\$35,000/\$35,001$\$ 50,000 / \$ 50,001-\$ 65,000 / \$ 65,001-\$ 80,000 / \$ 80,001-\$ 100,000 /$ over $\$ 100,000)$ 
How do you see yourself: are you generally a person who is fully prepared to take risks or do you try to avoid taking risks? (11-point likert-scale from $0=$ not at all willing to take risks to $10=$ very willing to take risks)

To what extent do you feel you can trust other people that you interact with in your daily life? (7point likert scale from $1=$ very little $\mathrm{t} 0$ 7=very much)

I would rather do something that requires little thought than something that is sure to challenge my thinking abilities. (7-point likert scale from $1=$ very untrue to $7=$ very true)

I trust my initial feelings about people. (7-point likert scale from 1=very untrue to $7=$ very true)

Which US political party do you identify with more strongly? (7-point likert scale from $1=$ strongly Republican to $4=$ neutral to $7=$ strongly Democratic)

How strongly do you believe in the existence of a God or Gods? (7-point likert scale from $1=$ very little to $7=$ very much)

Politically, how conservative are you in terms of social issues? (6-point likert scale from 1=very liberal to $6=$ very conservative)

Politically, how conservative are you in terms of fiscal issues? (6-point likert scale from 1=very liberal to $6=$ very conservative)

\section{Neutral}

Thanks for answering our questions

\section{$\underline{\text { Nudged }}$}

If you see a stranger in need, what do you think is the morally right thing to do? (available answers: help/don't help)

\section{Donation to Emergency}

We are collecting donations to send to Emergency. Emergency is a humanitarian NGO that provides emergency medical treatment to civilians victims of war. For more information, visit: www.emergencyusa.org

We would like to ask you if you would be willing to renounce to your 50c participation fee and donate it to Emergency. If you do so, we will not provide you a completion code so as you will not be allowed to submit the HIT. This means that your submission will NOT be rejected. Simply, your HIT will not be submitted.

(available answers: No, I do not want to donate my 50c participation fee to Emergency/Yes, I want to donate my 50c participation fee to Emergency) 


\section{Donation to Give for France}

You have probably heard about the terroristic attack in Nice last night, which killed at least 84 people, including several children.

We are collecting donations to send to Give For France. Give For France is a campaign to help victims of the Nice attack. For more information, visit: http:/www.giveforfrance.org/en

We would like to ask you if you would be willing to renounce to your 50c participation fee and donate it to Give For France. If you do so, we will not provide you a completion code so as you will not be allowed to submit the HIT. This means that your submission will NOT be rejected. Simply, your HIT will not be submitted.

(available answers: No, I do not want to donate my 50c participation fee to Give for France/Yes, I want to donate my 50c participation fee to Give for France)

\section{Study 5, Session 2}

The survey of Session 2 is identical to that of Session 1. The remaining part of the survey is slightly different.

\section{Neutral}

Thanks for answering our questions

\section{Nudged}

You are given 10c and an anonymous stranger is given nothing. You have the chance to give part of your money to the stranger.

The stranger has no choice: she or he has no chance to reciprocate your action.

What amount do you think it would be morally right to give to the stranger? (available answers: $0 \mathrm{c} / 1 \mathrm{c} / 2 \mathrm{c} / \ldots / 10 \mathrm{c})$

\section{Donation to Emergency}

We are collecting donations to send to Emergency. Emergency is a humanitarian NGO that provides emergency medical treatment to civilians victims of war. For more information, visit: www.emergencyusa.org

We would like to ask you if you would be willing to donate part of your 50c participation fee to Emergency.

If you decide not to donate money, we will provide you a completion code that you can use to 
submit this HIT to AMT and claim for the whole 50c.

If you decide to donate some money, we will not provide you a completion code for this survey. In order to pay you the amount that you decided to keep for yourself, we will redirect you to another survey, in which you will get this amount paid as a bonus.

How many cents would you like to donate to Emergency?

Please insert only a number between 0 and 50 .

(here there is a textbox in which participants could type their donation)

\section{Donation to Give for France}

You have probably heard about the terroristic attack in Nice last night, which killed at least 84 people, including several children.

We are collecting donations to send to Give For France. Give For France is a campaign to help victims of the Nice attack. For more information, visit: http://www.giveforfrance.org/en

We would like to ask you if you would be willing to donate part of your 50c participation fee to Give For France.

If you decide not to donate money, we will provide you a completion code that you can use to submit to AMT and claim for the whole 50c.

If you decide to donate some money, we will not provide you a completion code for this survey. In order to pay you the amount that you decided to keep for yourself, we will redirect you to another survey, in which you will get this amount paid as a bonus.

How many cents would you like to donate to Give For France?

Please insert only a number between 0 and 50 .

(here there is a textbox in which participants could type their donation)

\section{Study 5, Session 3}

The survey is identical to that of the previous sessions. The "donation to Emergency" and "donation to Give for France" screens are identical to those of Session 2. The "neutral" and "nudged" screen are slightly different.

\section{Neutral}

Consider the expression $10-\mathrm{x}$, for $\mathrm{x}$ that goes from 0 to 10 . 
Thus:

- if $x=0$, then $10-x=0$,

- if $x=1$, then $10-x=9$,

- $\quad \ldots$

- if $x=9$, then $10-x=1$,

- if $x=10$, then $10-x=0$.

We will now ask you two simple comprehension questions to make sure that you understand the situation.

What number $\mathrm{x}$, between 0 and 10, MAXIMIZES the equation 10 - $\mathrm{x}$ ? (available answers:

$0 / 1 / 2 / \ldots / 10)$

What number $\mathrm{x}$, between 0 and 10, MINIMIZES the equation 10 - $\mathrm{x}$ ? (available answers:

$0 / 1 / 2 / \ldots / 10)$

\section{Nudged}

You are given 10c and an anonymous stranger is given nothing. You have the chance to give part of your money to the stranger.

The stranger has no choice: she or he has no chance to reciprocate your action.

We will now ask you some questions to make sure that you understand the situation.

What amount should you give to the stranger in order to maximize your payoff?

What amount should you give to the stranger in order to maximize their payoff?

The comprehension questions are over.

It's time to make your real choice.

What do you think is the morally right thing to do? (available answers: Give 0c/Give 1c/Give $2 \mathrm{c} / . . . /$ Give $10 \mathrm{c})$ 